\title{
Plastik Enjeksiyon Tezgâhlarında Vida Kırılmasının Akustik Emisyon Yöntemi ile Tespit Edilmesi
}

\author{
Halil Kılıç ${ }^{1 *}$, Mustafa Timur² \\ ${ }^{1 *}$ Kırklareli Üniversitesi, Teknik Bilimler MYO, Makine Programı, Kırklareli, Türkiye, (ORCID: 0000-0001-6182-356X), \\ hali1.kilic@klu.edu.tr \\ 2 Adnan Menderes Üniversitesi, Mühendislik Fakültesi, Makine Mühendisliği Bölümü, Aydın, Türkiye, (ORCID: 0000-0002-4569-0450), \\ mustafa.timur@adu.edu.tr
}

(1st International Conference on Applied Engineering and Natural Sciences ICAENS 2021, November 1-3, 2021)

(DOI: $10.31590 /$ ejosat.991899)

ATIF/REFERENCE: Kılıç, H. \& Timur, M. (2021). Plastik Enjeksiyon Tezgâhlarında Vida Kırılmasının Akustik Emisyon Yöntemi ile Tespit Edilmesi. Avrupa Bilim ve Teknoloji Dergisi, (28), 126-129.

$\ddot{\mathbf{O z}}$

Günümüzde dünyada plastik üretimi 400 milyon tona ulaşmışıtır. Bu büyük artışta plastik ürün tasarımı, kalıp imalatı ve plastik enjeksiyon makinelerinin rolü oldukça fazladır. Dolayısıyla üretimde oluşabilecek problemlerin önceden tespit edilmesi ve gerekli önlemlerin alınması üretim verimliliği bakımından büyük önem arz etmektedir. Plastik Enjeksiyon tezgâhları günümüzde üretimin yoğun olarak yapıldı ̆̆ı ve ürün kalitesinin makine performansına göre değerlendirildiği tezgâhlardır. Tezgâhların 7/24 saat çalışması ve bakım süreçlerinin zamanında yapılamaması, vida mili kırılması, hidromotor ve işlemci arızaları gibi üretimde problemlere neden olmaktadır. Bu problemlerin giderilmesi büyük maliyetler ve üretimde zaman kaybına neden olmaktadır. Özellikle vida mili arızasında tezgâh tamamen kontrol dışı olmakta ve 3-4 aylık zaman diliminde vida mili yenisi ile değiştirilerek tekrar çalışmaktadır. Bu çalışmada, plastik enjeksiyon tezgahlarında meydana gelen vida mili kırılma probleminin üretim esnasında oluşmaması için kesme kuvveti sinyallerinin akustik emisyon kullanılarak önceden tahmin edilmesi amaçlanmaktadır. Böylece yukarıda bahsedilen problemler önceden tespit edilerek üretimde meydana gelebilecek aksamaların önüne geçilmiş olacaktır.

Anahtar Kelimeler: Plastik enjeksiyon, Vida mili, Akustik emisyon.

\section{Detection of Screw Breakage in Plastic Injection Machines by Acoustic Emission Method}

\begin{abstract}
Today, plastic production in the world has reached 400 million tons. Plastic product design, mold manufacturing and plastic injection machines play a significant role in this huge increase. Therefore, it is of great importance to determine the problems that may occur in production and to take the necessary precautions in terms of production efficiency. Plastic Injection machines are machines where production is made intensively and product quality is evaluated according to machine performance. The 24/7 operation of the benches and the lack of timely maintenance processes cause problems in production such as screw shaft breakage, hydromotor and processor failures. Elimination of these problems causes great costs and loss of time in production. Especially in case of screw shaft failure, the machine is completely out of control and works again by replacing the screw shaft with a new one in 3-4 months. In this study, it is aimed to predict the cutting force signals using acoustic emission so that the screw shaft breakage problem that occurs in plastic injection benches does not occur during production. In this way, the above-mentioned problems will be determined in advance and the disruptions that may occur in production will be prevented.
\end{abstract}

Keywords: Plastic injection, Screw shaft, Acoustic emission.

*Sorumlu Yazar: halil.kilic@,klu.edu.tr 


\section{Giriş}

Enjeksiyon kalıplama tekniği, karmaşık geometrilere sahip parçaların yanı sıra çeşitli şekil ve boyutlarda parçalar üretmek için kullanılır. Plastik enjeksiyon kalıplama, plastik parçaların üretimi için uygulanan en yaygın işlemlerden biridir. Enjeksiyon işlemi, yüksek basınç altında ve yüksek hızlarda kalıbın sıcak eriyik ile doldurulduğu döngüsel bir süreçtir. Bunu, ortaya çıkan formun (ürün) kalıp içinde soğutulması ve son aşamada ürünün kalıptan çıkarılması izler (Rosato 2000). Bu döngü tipik olarak yaklaşık 20 sn sürer (Kozjek ve diğer. 2019). Enjeksiyon kalıplamanın çeşitli avantajlarına ve uygulamalarına rağmen, göz önünde bulundurulması gereken bazı faktörler, enjeksiyon basınc1, kalıp sıcaklığı, plastik eriyik sıcaklığı, soğutucu sıcaklığı, kalıptan çıkarma metodu ve makine teçhizatların bakımıdır.

Bazı araştırmacılar yaptıkları çalışmalarda, üretim hattında meydana gelebilecek problemlerin önceden kestirimi için farklı uygulamalarda faydalı olabilecek çerçeveler sunmuştur. Jemielniak, takım aşınmasının izlenmesinde ve parça kopmasında akustik emisyon (AE) sensörü kullanarak çalışmalar yapmış ve takımda meydana gelen krater aşınmalarını bu sayede incelenmiştir (Jemielniak 2000). İnasaki ve diğer., tornalama işleminde, akustik emisyon sensörü kullanarak yapay sinir ağları yardımıyla talaş yapısı ve tırlamanın belirlenmesi üzerine çalışmalar yapmıştır (Inasaki 1998). Dolinsek ve Kopac, AE jet sensörü yardımıyla tornalama işleminde kullanılan farklı tip kesici uçlar ve takım kaplamalarında meydana gelen aşınmaları tespit etmiştir. AE sinyalleri incelendikten sonra spektral analizi yapılarak genlik frekansı grafiklerini oluşturmuşlardır (Dolinsek ve Kopac 1999). Lee ve diğer., piezo elektrik ve AE kuvvet sensörü ile tornalama işleminde takım kırılmasının belirlenmesi üzerine çalışmalar yapmıştır. Yaptıkları çalışmada, AE sinyallerinin genliğinde meydana gelen ani artış ve akabinde kesme kuvvetinde meydana gelen ani değişimlerle takım kırılmasını incelemişlerdir (Lee ve diğer. 2006). Jamielniak ve diğer., yaptıkları çalışmada kesici takımlarda meydana gelen kopma aşınmasının tespitinde $\mathrm{AE}$ sensörü kullanmıştır. AE sinyallerinin enerjisini belirleyen RMS (root mean sensör), ani bir artış gösterdiği için tercih edilmiş ancak ani değişimlerde RMS değerleri çokta başarılı olamamıştır. Bunun Yerine CTF (telafisi olmayan takım kaybı) değerleri kullanarak başarılı sonuçlar elde etmişlerdir (Jamielniak ve diğer. 1998). Kalyoncu yapmış olduğu çalışmada, makine ve elemanlarında meydana gelen arızaların belirlenmesinde, titreşim analiz metodu ve kestirimci yöntemden bahsetmiştir. Örnek uygulamada, rulmanlarda meydana gelebilecek arızalar irdelenmiştir. $\mathrm{Bu}$ amaçla, titreşim ölçümleri ve analizleri yapılarak tespit edilen sınır değerleri ve yeni trendler göz önünde bulundurularak yapılan karşılaştırmaların, makine ve elemanlarının geçmişinin nasıl izlendiği, hâlihazırdaki durumu ve gelecekteki çalışma durumu hakkında yapılacak tahminler üzerinde durulmuştur (Kalyoncu 2006). Engür ve diğer., titreşim analiziyle kestirimci bakım yöntemini irdelemiş, döner makinelerde oluşan eksen bozukluğu, dengesiz dönme, rulman hasarları ve mekanik gevşemeler gibi meydana gelen problemlerin daha hızlı ve daha düşük maliyetle tespit edilebileceği ve ileride oluşabilecek daha büyük kayıpların azaltılabileceği bildirilmiştir (Engür 2007). Choudhury ve diğer., kendi deney düzenekleri ile rulman hasarlarının tespitinde $\mathrm{AE}$ yönteminin kullanılabilirliğini araştırmışlardır. Bu amaçla orijinal rulman ile bilye ve bilezik yuvarlanma yolu üzerinde farklı hasar derecelerine sahip rulmanların, farklı yük koşulları altındaki AE ölçümlerini yapmıştır (Choudhury ve Sirinivas 2004). Van Brussel ve diğer., sonlu elemanlar yöntemiyle vidalı mil hareket sisteminide içeren üç eksene sahip freze tezgahını modellemiştir. Komponent modu ile sonlu elemanlar modelini kontrol ve simulasyon için uygun durum uzay modeli şekline indirgemiştir (Brussel ve diğer. 2001). Schafers ve diğer. tarafindan yapılan çalışmada, freze takım tezgâhı bütünüyle sonlu elemanlar yöntemiyle modellenerek yüksek hılı tezgâhların kontrolünde ve dizaynında kullanılabileceği gösterilmiştir (Schafers ve diğer. 2006). Chen ve diğer., vidalı mil hareket sistemini yaylarla bağlı rijit modeller olarak ifade etmiştir. Model vida milindeki eksenel hareketi, burulma hareketini ve kızakların bağlantı noktalarında oluşan kaçıklığı ifade etmektedir. Bu modelle, kızaklarda oluşan yer değişiminin tablanın konum doğruluğuna büyük oranda etki ettiği gösterilmiştir (Chen ve Leonard 2018).

Vida mili ile somunun birleşme yüzeyi, hareket iletmede, titreşimlerde ve vidalı milden tablaya iletilen kuvvetler önemli rol oynamaktadır. Bu amaçla vida ile somun arasındaki bağıntı dinamiğinin ifadesi için birçok çalışma yapılmıştır (Cuttino ve Dow 1997) (Cuttino ve diğer. 1997) (Lin ve diğer. 1994) (Wei ve Lin 2003). Vida mili hareket sisteminin sonlu elemanlar yöntemiyle modellendiğinde vida ile somun ara yüzeyindeki bağıntının özel riijitlik matrisiyle modellenmesi gerektiği bildirilmiştir. $\mathrm{Bu}$ özel matrisi oluşturabilmek için araştırmacılar vida milinin eksenel ve burulma yer değişimlerini ifade etmişlerdir. Ancak yapılan modellemelerde vida-somun arasındaki eksenel, burulma ve dikey yöndeki yer değiştirmelerin birlikte olduğu çapraz bağlantı davranışlarının ifadesi yapılamamıştır. $\mathrm{Bu}$ hareketler sistem dinamiğini ortaya koyma bakımından önemlidir. AE sensörü ile yapılan bu çalışma, vida mili üzerine etki eden karşı kuvvetlerin tespit edilmesinde katkı sağlayacaktır.

\section{Materyal ve Metot}

Vida, uzunluk ve çaplarıyla bağlantılı olarak tanımlanır. Vidalar kullanılacak malzemeye göre farkl1lık gösterse de genellikle üç bölgeden oluşmaktadır. Şekil 1'de görüldüğü gibi bu bölgeler, beslenme, sıkıştırma ve ölçme bölgeleridir. Besleme bölgesi; tanecik halinde katı malzemeyi sıkıştırma bölgesine doğru iter. Sıkıştırma bölgesi; malzemenin sıkıştırılarak eritme işleminin büyük bölümünün gerçekleştirildiği kısımdır. Ölçme bölgesi; eritme işleminin tamamlanarak erimiş malzemeyi vida kısmının ön tarafına iletildiği kısımdır. Vida, biriken malzemenin karşı basıncı ile kalıbı doldurmak için yeterli miktarda malzeme birikinceye kadar geri itilir (Purde ve Özden 2005).

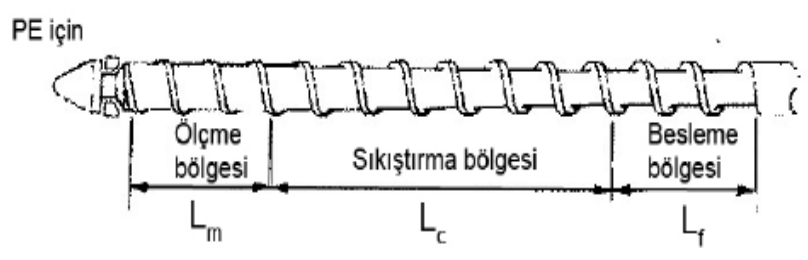

Şekil 1. Vida mili

Vida mili malzemesinde M6 N66 polyamid cam elyaf katkılı malzemeler kullanılmaktadır. $\mathrm{Bu}$ malzemeler aşındırıcı özelliğinden dolayı diğer malzemelere göre üstün mukavemet 
sağlar (Altıntaş 2012). Bu çalışmadaki deneyler Demark S20201 marka plastik enjeksiyon tezgahında gerçekleştirilmiştir. Deney sırasında yüzey algılama probunun dinamoya yerleştirilmesi için uygun bir çalışma yapılmıştır. Vida milinin çalışması makinenin cycle time (devir zamanı) için oldukça önemlidir. Malzeme özelliklerine göre 11, 14 ve 21 sn olmak üzere 3 farklı devir seçimi yapılmıştır.

Malzeme seçiminde ise plastik sektöründe en çok kullanılan malzeme olan; PET (polietilen tereftalat) kapak, Polipropilen (PP) ve \%30 kırık PET olmak üzere üç farklı tip malzeme tercih edilmiştir. Deneylerde kullanılan malzemeler Şekil 2'de görülmektedir.

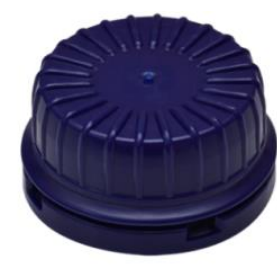

(a)

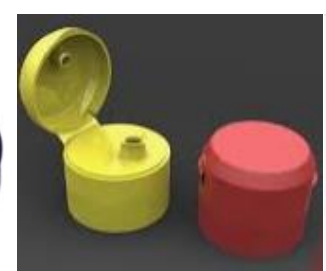

(b)

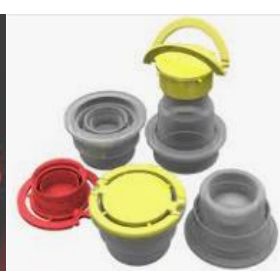

(c)
Şekil 2. Kullanılan malzemeler, a) PET kapak, b) PP, c) \%30 kırı PET

Şekil 3'te, akustik emisyon ölçümünde kullanılan kistler marka sensör görülmektedir. Sensör $50-400 \mathrm{kHz}$ aralığında ölçüm yapmaktadır. Paslanmaz çelikten üretilmiş ve vida miline kırılmanın olabileceği en yakın noktaya yerleştirilmiştir. AE sensöründen alınan sinyaller yüksek ve düşük geçiş filttrelerinden geçirilerek gürültünün olmadığı ortamda veri toplama kartına iletilir. Burada analog sinyaller dijital sinyale dönüştürülerek bilgisayara aktarılır.

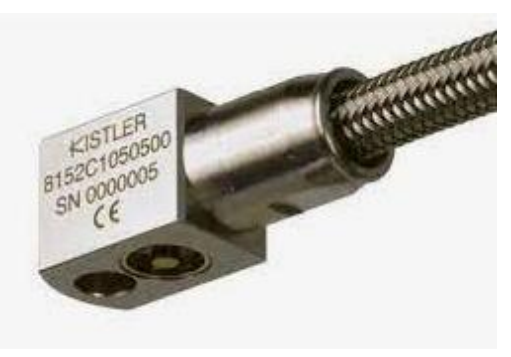

Şekil 3. AE sensörü

Vidanın çalışması esnasında aşınma, kırılma, parçacık ayrılması ve kesme kuvveti ölçümleri amaçlanmıştır. Şekil 4'te görüldüğü gibi bu parametrelere bağlı olarak AE sinyallerindeki değişimi kapsayan bir blok şeması ile çalışma planlanmıştır. Vida milinin kırılmalara en fazla maruz kaldığ 1 bölge olan hidromotor bölgesinde meydana gelen burç aşınması merkez kuvveti zayıflatmakta ve hareketin doğrusal olarak iletilmesini engellemektedir. $\mathrm{Bu}$ durum milin aşırı zorlanmalarına ve zamanla kırılmasına yol açmaktadır. Bu nedenle deney düzeneği bu bölgeye yerleştirilmiştir. Dinamometre ve sicaklık sensöründen alınan kuvvet ve sicaklık sinyalleri doğrudan bilgisayara aktarılmıştır. AE sensöründen alınan sinyaller ise önce kuplöre ardından veri toplama kartına sonrada bilgisayara aktarılmaktadır.

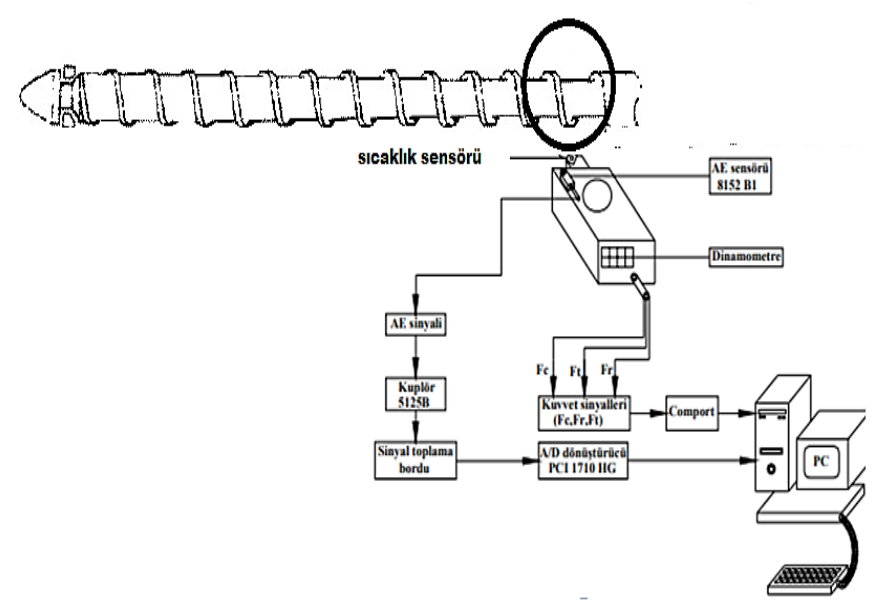

Şekil 4. Vida mili ve AE sensörünün konumlandırılması

Kullanılan infrared sıcaklık ölçer ve dinamometre Şekil 5'te gösterilmektedir. Dinamometre (TELC DKM 2010) saniyede ortalama 20 ölçüm yapabilmekte ve üç eksende kuvvet ölçümü yapabilmesinin yanı sıra vida milinde meydana gelen sıcaklığ 1 da ölçebilmektedir. 45-60-75-90 'lik açılarla sistem üzerine konumlandırılabilmektedir. Ölçülen değerler bilgisayara kaydedilmektedir.

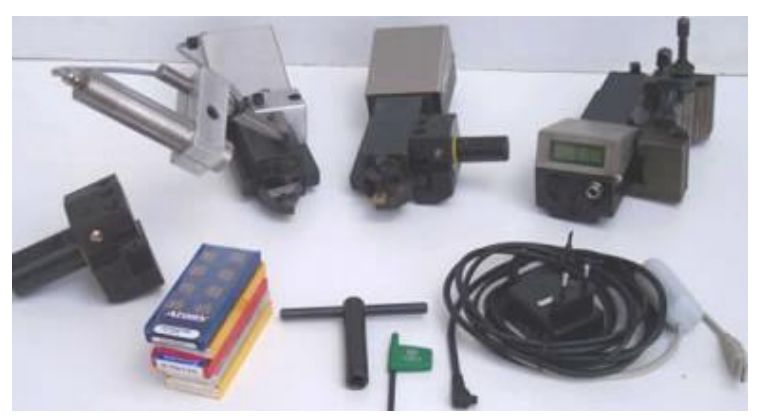

Şekil 5. Infrared sıcaklık ölçer ve dinamometre

\section{Araştırma Sonuçları ve Tartışma}

Deneylerde kullanılan veri toplama kartı 2 analog çıkış ve 8 dijital girişe sahiptir. Kırılma işlemi anlık olduğu için kart yüksek veri işleme kapasitesine sahiptir. Yapılan çalışmanın her bir testinde farklı numune kullanılmıştır. Deneysel numunelerin üretim özellikleri Tablo 1'de özetlenmiştir.

Tablo 1. Deneysel parçaların üretim parametreleri

\begin{tabular}{c|l|c|c|c}
\hline No & Deneysel parametreler & $\mathbf{P X}_{\mathbf{1}}$ & $\mathbf{P X}_{\mathbf{2}}$ & $\mathbf{P X}_{\mathbf{3}}$ \\
\hline 1 & Kullanılan malzeme & PET & PP & $\begin{array}{c}\% 30 \\
\text { kırık PET }\end{array}$ \\
\hline 2 & Cycle time $($ sn $)$ & 11 & 14 & 21 \\
\hline 3 & Kalıp göz kavitesi $($ adet $)$ & 8 & 8 & 8 \\
\hline 4 & Chiller su sıcaklığ $\left({ }^{\circ} \mathrm{C}\right)$ & 10 & 12 & 14 \\
\hline 5 & Boya kullanımı & Siyah & Sarı & Şeffaf \\
\hline
\end{tabular}

$\mathrm{PX}_{1}$ numunesinin üretim esnasında vida milindeki $\mathrm{AE}$ değeri $14 \mathrm{mV}$ olarak ölçülmüştür. Sicaklık $305{ }^{\circ} \mathrm{C}$, makine cycle time 11 sn ve ilerleme $0.172 \mathrm{~mm} / \mathrm{dev}$ olarak ölçülmüştür. $\mathrm{PX}_{2}$ numunesin üretim esnasında vida milindeki AE değeri $18 \mathrm{mV}$ 
olarak ölçülmüştür. S1caklığ $320^{\circ} \mathrm{C}$, makine cycle time 14 sn ve ilerleme $0.172 \mathrm{~mm} / \mathrm{dev}$ olarak ölçülmüştür. $\mathrm{PX}_{3}$ numunesinin üretim esnasında vida milindeki $\mathrm{AE}$ değeri $25 \mathrm{mV}$ olarak ölçülmüştür. Sicaklık $310{ }^{\circ} \mathrm{C}$, makine cycle time $21 \mathrm{sn}$ ve ilerleme değeri $0.172 \mathrm{~mm} / \mathrm{dev}$ olarak ölçülmüştür.

$\mathrm{Bu}$ çalışmada girdi parametrelerinin çıktı parametrelerini nasıl etkilediğini görmek amacıyla ilerleyen mil aşınması ve mil kırılmasını tahmin etmek için deneyler yapılmıştır. Ayrıca bu çalışmada min $\mathrm{AE}$ ve min sıcaklık değerlerinin incelenmesi sağlanmıştır. Sıcaklık arttıkça AE 'ye olan etki azalmaktadır. $\mathrm{PX}_{2}$ poliproplen malzemesinin sicaklık değeri en yüksek olan $320{ }^{\circ} \mathrm{C}$ 'dir. $\mathrm{Bu}$ durum $\mathrm{AE}$ emisyon değerini düşürmüştür. $\mathrm{PX}_{3}$ malzemesine katılan kırık plastik özelliklerinden dolayı sıcaklık değeri $310^{\circ} \mathrm{C}$ olarak ölçülmüş ancak $\mathrm{AE}$ değeri $25 \mathrm{mV}$ 'dir. $\mathrm{AE}$ değerinin yüksek olmasının nedeni vida milinde meydana gelen zorlanmalar PET hammaddenin vida içerisinde zorlanarak ilerlediği ve kırık PET kullanımı esnasında meydana gelebilecek olan aşındırıcı yabancı malzemelerin olması ile açıklanabilir. $\mathrm{Bu}$ tarz yabancı madde vida içerisinde yeterince erimemekte ve ilerleme esnasında kalıbın çalışma şekline ve hidromotor bronz burç aşınmalarına neden olmaktadır. Bu durumdan dolayı vida mili ile hidromotor ekseni arasında kaçıklık oluşmakta ve vida milinin maruz kaldığı olumsuz durumdan dolayı kırılmalar meydana gelmektedir. $\mathrm{PX}_{1}$ deney malzemesi üretim özellikleri bakımından herhangi bir problem oluşturmamıştır. Kullanılan hammaddenin orijinal PET malzeme olması ve uygun sicaklık değerlerinde olması AE değerinde istenilen değerleri oluşturmuştur.

\section{Sonuç}

$\mathrm{Bu}$ çalışmada, vida milinde meydana gelen aşınma ve kırılma hasarlarının öncesinde tespit edilebilmesi için bir dizi deneyler yapılmıştır. Deneyler sonucunda vida mili kırılmasına sebep olacak parametrelerin başında PET hammaddenin özelliği önem taşımaktadır. Dolayısıyla vida mili içerisinde erimiş plastik sağlıklı bir ilerleme sağlar ve kalıp içerisinde herhangi bir hata oluşturmaz ise vida mili ve kovanında da herhangi bir problem meydana gelmemektedir. Bu durum yapılan deneysel çalışma ile ispatlanmıştır. $\mathrm{PX}_{3} \% 30$ kırık PET karışımlı malzeme ise vida milindeki ilerlemesi esnasında problem oluşturmuş ve $\mathrm{AE}$ değerini yükseltmiştir. Fakat diğer katkısız $\mathrm{PX}_{1}$ ve $\mathrm{PX}_{2}$ 'de böyle bir durum görülmemiştir. Vida milinin çalışması esnasında en fazla zorlanmalara maruz kaldığ 1 durum ise hidromotor çıkış burcudur. Kirılmalar çoğunlukla bu bölgede meydana gelmektedir. Bu durumu azaltmak için ise vida milinin bakım sürecinin zamanında yapılması, orijinal (katkısız) hammadde kullanılması ve vida iç sıcaklığının homojen bir dağılım sağlaması önerilmektedir.

\section{Kaynakça}

Altıntaş, Y., (2012). Üretim otomasyonu: Metal kesme mekaniği, takım tezgâhı titreşimleri ve bilgisayarlı sayısal denetim tasarımı. Cambridge University Press.

Brussel, V., Sas, P., Istvan, N., De Fonseca, P. \& Van Den Braembussche, P. (2001). Towards a Mechatronic Compiler. Transactions on Mechatronics, Vol. 6, No. 1, p. 90-105.

Chen, S. \& Leonard, W. J. (2008). Tool failure determine acouistic emission signal. Journal of Materials Processing Technology, Vol. 153-154, p. 128-135.
Choudhury, S. K. \& Sirinivas, P. (2004). Tool wear prediction in turning. Journal of Material Processing Technology, Vol. 153-154, p. 276-280.

Cuttino, J.F. \& Dow, T.A. (1997). Contact between Elastic Bodies with an Elliptic Contact Interface in Torsion. Journal of Applied Mechanics, Vol. 64, p. 144-148.

Cuttino, J. F., Dow T. A., \& Knight, B.F. (1997). Analytical and Experimental Identification of Nonlinearities in a SingleNut Preloaded Ballscrew. Journal of Mechanical Design, Vol. 119, p. 15-19.

Dolinsek, S. \& Kopac, J. (1999). Acoustic emission signals for tool wear identification. Wear, Vol. 225-229, p. 295-303.

Engür, A. İ. (2007). Kestirimci bakımda titreşim analizi. Mühendis ve Makine, Vol. 48, p. 27-31.

Inasaki, I. (1998). Application of acoustic emission sensor for monitoring machining process. Ultrasonics, Vol. 36, p. 273281.

Jamielniak, K. \& Otman, O. (1998). Tool failure detection based on analysis of acoustic emission signal. Journal of Material Processing Technology, Vol. 76, p. 192-197.

Jemielniak, K. (2000). Some expect of AE aplication in tool condition monitoring. Ultrasonics, Vol. 38, p. 604-608.

Kalyoncu, M. (2006). Titreşim analizi ile makine elemanları arızalarının belirlenmesi. Mühendis ve Makine, Vol. 47, p. 28-35.

Kozjek, D., Vrabič, R., Kralj, D., Butala, P. \& Lavrač, N. (2019). Data mining for fault diagnostics: A case for plastic injection molding. Procedia CIRP., Vol. 6, p. 809-814.

Lee, D., Hwang, I., Valente, C. M., Oliveira, J. \& Dornfeld, D.A. (2006). Precision manufacturing process monitoring with acoustic emission. International Journal of Machine Tools and Manufacture, Vol. 46, No. 2, p. 176-188.

Lin, M.C., Ravani, B. \& Velinsky, S.A. (1994). Kinematics of the Ball Screw Mechanism. Journal of Mechanical Design, Vol. 116, p. 849-855.

Purde, Ö. \& Özden, D. (2005). Plastik enjeksiyon kalıbı. Yüksek Lisans Tezi, Yıldız Teknik Üniversitesi, İstanbul, Turkiye.

Rosato, D. V. \& Rosato, M. G. (2000). Injection Molding Machines. Injection Molding Handbook, p.28-150, Springer Boston, MA.

Schafers, E., Denki J. \& Hamann J. (2006), Mechatronic Modeling and Analysis of Machine Tools. Proceedings of the 2nd International Conference on High Performance Cutting, Canada.

Wei, C.C. \& Lin, J.F. (2003). Kinematic Analysis of the Ball Screw Mechanism Considering Variable Contact Angles and Elastic Deformations. Journal of Mechanical Design, Vol. 125, p. 717-733. 